\title{
MINIREVIEW
}

\section{rRNA Sequence Comparisons for Assessing Phylogenetic Relationships among Yeasts}

\author{
C. P. KURTZMAN \\ Microbial Properties Research, National Center for Agricultural Utilization Research, \\ Agricultural Research Service, U.S. Department of Agriculture, \\ Peoria, Illinois 61604
}

\section{INTRODUCTION}

The molecular methods used for measuring levels of genetic relatedness among yeasts and many other organisms trace their beginnings to comparisons of nuclear DNA complementarity. This technique, which is still useful and is used widely by microbial taxonomists, has been calibrated for yeasts by comparing strains that exhibit various degrees of sexual fertility and has been found to discriminate no further than to closely related species $(24,28)$. While quantification of whole genomic DNA duplex formation is exceptionally useful for determining whether isolates that exhibit various degrees of phenotypic differences represent the same or different species, the results obtained with this method do not answer the larger question of how more highly divergent species are related.

Because comparisons of rRNA sequence divergence resolve at greater distances than measurements of nuclear DNA complementarity, such comparisons are being widely used for estimating phylogenetic relationships among various kinds of organisms. The use of rRNA comparisons has led to marked changes in the way in which bacterial relationships are now viewed (52), and we can expect similar changes in our perception of the systematics of other groups once they have undergone the same molecular scrutiny. The interest in rRNA comes from two important properties: (i) ribosomes are present in all cellular organisms and almost certainly share a common evolutionary origin, thus providing a genetic map that charts the positions of all living things, and (ii) some rRNA sequences are sufficiently conserved that they are homologous for all organisms and serve as reference points, enabling alignment of less conserved areas for measurement of changes over varying evolutionary distances. Other molecules that have these same properties are also useful for phylogenetic measurements, but the methods used for comparing them are often less rapid than the methods used for comparing nucleic acids.

In this review I describe the impact that rRNA comparisons are beginning to have on our understanding of evolutionary relationships among yeasts. The yeasts represent a unique group of fungi that are characterized by vegetative growth that is predominantly unicellular and by the formation of sexual states which are not enclosed in fruiting bodies. The phylogenetic diversity of these morphologically simple fungi is underscored by the finding that some species have ascomycetous life cycles, whereas others are basidiomycetes and exhibit phenotypic similarities with the smut fungi. The use of rRNA comparisons should allow a deciphering of the relationships among extant taxa and also answer the question of whether yeasts represent ancestral forms of the higher fungi or are reduced forms of many present-day groups and thus of polyphyletic origin.

\section{rRNAs AND METHODS FOR ISOLATION}

rRNAs occur in several size classes in eukaryotes; the genes coding for large (25S to $28 \mathrm{~S}$ ), small (18S), and $5.8 \mathrm{~S}$ rRNAs occur as tandem repeats with as many as 100 to 200 copies. The separately transcribed 5S rRNA gene may also be included in the repeats (16). As discussed below, each of the rRNA size classes has been examined for the amounts of phylogenetic information that may be provided.

The large quantities of rRNAs expressed by cells make the isolation and purification of these molecules relatively easy despite the nearly ubiquitous occurrence of quite stable RNases. Numerous methods for isolation and purification have been described. Those used in my laboratory (27) are generally satisfactory and represent a modification of the procedures of Chirgwin et al. (11). Methods used for the isolation and characterization of ribosomal DNA (rDNA) have been described by White et al. (51) and Vilgalys and Hester (46).

\section{ESTIMATES OF RELATEDNESS FROM rRNA-rDNA REASSOCIATION}

The first extensive use of rRNA comparisons for yeast systematics was described by Bicknell and Douglas (5), who measured extents of divergence from amounts of reassociation between tritium-labeled $25 \mathrm{~S}$ rRNAs and complementary sites on filter-bound nuclear DNAs. The results of these authors demonstrated that there are relatively high levels of relatedness among a group of species now assigned to the genera Saccharomyces, Kluyveromyces, Zygosaccharomyces, Torulaspora, and Arxiozyma and lower amounts of relatedness between these taxa and certain other taxa, such as Pichia jadinii (anamorph, Candida utilis). A similar methodology was used by Segal and Eylan $(42,43)$ for comparisons among species of the genus Candida, including Candida albicans. Baharaeen and Vishniac (3) examined relationships among the basidiomycetous yeasts by measuring the extent of reassociation between rRNAs and complementary DNAs. One result of this work was the demonstration that the red yeasts Rhodosporidium toruloides and Sporidiobolus salmonicolor are less closely related to each other than $\boldsymbol{R}$. toruloides and the non-carotenoid producer Leucosporidium scottii are, a finding somewhat at variance with relationships that were determined from an examination of the partial sequences of large-subunit rRNAs (13).

Although rRNA-rDNA hybridizations provide an over- 
view of relatedness between taxa, they are labor intensive because each comparison requires that the strains of interest be paired. Furthermore, as evolutionary distances increase, a point is reached at which there is insufficient base sequence similarity to allow duplexing of paired molecules. It has been suggested that sequences must exhibit 75 to $80 \%$ or greater similarity before reassociation can occur $(8,10)$. As a consequence of this threshold, $R$. toruloides exhibited the same low level of background relatedness to the ascomycete Williopsis (Hansenula) saturnus as it did to the basidiomycete Ustilago maydis (3).

\section{RESTRICTION FRAGMENT LENGTH POLYMORPHISMS OF RDNA}

Because rDNA occurs as multiple copies, it lends itself to analysis based on restriction fragment length polymorphisms. Magee et al. (35) treated rDNAs from several medically important Candida species with a variety of restriction endonucleases and concluded that Candida guilliermondii, Candida tropicalis, and Candida albicans produced sufficiently different digestion patterns to allow recognition of each species. Similar results were obtained by Laaser et al. (30) for the basidiomycetous species Cryptococcus humicolus and Trichosporon cutaneum and by Vilgalys and Hester (46) for several additional species of the genus Cryptococcus. Lachance (31) used restriction fragment length polymorphism patterns to map the genetic profiles of 125 isolates of the cactus yeast Clavispora opuntiae that had been collected worldwide. Nearly all of the restriction sites that allowed discrimination of individual strains were located in the hypervariable intergenic spacer region.

Data obtained from the studies described above show that restriction fragment length polymorphism patterns are sufficiently different to allow recognition of individual species, as well as individual strains of a species. Consequently, the method has considerable diagnostic value. Estimates of evolutionary relationships based on restriction fragment length polymorphism patterns have been reported for species assigned to the genera Candida (35) and Cryptococcus (46). Such estimates would be expected to be less accurate than estimates derived from sequence comparisons as evolutionary distances increase and the extent of pattern similarities becomes less certain.

\section{SEQUENCING OF rRNA}

Methods for sequencing nucleic acids are now commonplace. The techniques used for 5S rRNA sequencing have been summarized and discussed by Walker (48). The procedures used for sequencing large- and small-subunit rRNAs are generally based on the dideoxy method of Sanger et al. (41), and Lane et al. (33) have described the application of this method with oligonucleotide primers and reverse transcriptase. More recently, rDNA has been copied by the polymerase chain reaction and sequenced (51). The sequences generated by polymerase chain reactions usually have fewer artifacts than those synthesized by the reverse transcriptase method, but the latter method is more likely to allow detection of nucleotide heterogeneity at specific sites because the preparations contain the expressed products of many genes, whereas the polymerase chain reaction may amplify only a few of the many genes coding for rRNA.

\section{S rRNA}

Because of the conserved nature and small size (ca. 120 nucleotides) of 5 S rRNAs, their sequences are easily determined and have been widely used for estimating broad phylogenetic relationships (23). Walker and Doolittle (49) compared 5S rRNAs from eight basidiomycetes, including four yeasts, and concluded that sequence similarity correlated with the structure of hyphal septa (i.e., simple pores versus dolipores). On the basis of additional $5 \mathrm{~S}$ comparisons, Gottschalk and Blanz (17) reported that contrary to expectation, rust fungi, which have simple septal pores, cluster with the group defined by Walker and Doolittle as having dolipore septa. Guého et al. (19) used partial sequences of $18 \mathrm{~S}$ and $25 \mathrm{~S}$ rRNAs to compare basidiomycetous yeasts, some of which were included in the studies of Walker (47) and Blanz and Gottschalk $(6,7)$. The relationships determined from these partial sequences were similar to those derived from $5 \mathrm{~S}$ rRNA comparisons.

The studies of $5 \mathrm{~S}$ rRNAs from ascomycetous yeasts have been less extensive than the studies of $5 \mathrm{~S}$ rRNAs from basidiomycetous species. Mao et al. (36) described the $5 \mathrm{~S}$ sequence of Schizosaccharomyces pombe and noted that this sequence differed sufficiently from the Saccharomyces cerevisiae sequence to suggest that these two organisms are phylogenetically quite divergent. Similar results were obtained by Walker (48), who showed that an apparent cluster formed by the genera Schizosaccharomyces and Protomyces was well separated from a second group comprising the genera Saccharomyces, Nadsonia, Lipomyces, and Yarrowia.

\section{SMALL-SUBUNIT (18S) AND LARGE-SUBUNIT (25S TO 28S) rRNAS}

The larger sizes of small-subunit rRNAs (ca. 1,800 nucleotides) and large-subunit rRNAs (ca. 3,200 nucleotides) compared with $5 \mathrm{~S}$ and $5.8 \mathrm{~S}$ rRNAs provide an opportunity for greater resolution of phylogenetic relationships. In addition, comparisons of sequences from a wide variety of organisms have shown that for both large- and small-subunit rRNAs, different regions have different rates of nucleotide substitution $(12,21)$. Because of this, the molecules are regarded as a collection of chronometers, with each region offering a different glimpse of the evolutionary history of an organism (52).

Despite recent advances in sequencing technology, the determination of complete sequences is laborious, and only a few hundred complete sequences are available for either the large subunits or the small subunits $(12,21)$. Partial sequences are relatively easy to determine by using primer extension methods and form the basis for most phylogenetic comparisons. McCarroll et al. (37) and Lane et al. (33) demonstrated that partial sequences of small-subunit rRNAs reveal essentially the same phylogenetic relationships as complete sequences.

In order to understand the genetic resolution that rRNA sequence differences provide among yeasts, Peterson and Kurtzman (40) examined six ca. 200-nucleotide regions by using as references genetically defined sibling species pairs belonging to three genera. Four of the regions selected were from the small subunit and were expected to be rather conserved (12). The two other regions were from the large subunit; for other organisms, one of these regions is highly variable, while the other is more conserved (21). A summary of the findings is given in Table 1 , which shows that the 
TABLE 1. Extent of rRNA sequence divergence among sibling yeast species

\begin{tabular}{|c|c|c|c|c|c|c|}
\hline \multirow[t]{2}{*}{ Species pair } & \multirow[t]{2}{*}{$\begin{array}{c}\text { \% DNA } \\
\text { relatedness }^{a}\end{array}$} & \multirow[t]{2}{*}{ Mating response $^{a}$} & \multirow[t]{2}{*}{$\begin{array}{l}\text { Ascospore } \\
\text { viability }^{a}\end{array}$} & \multicolumn{3}{|c|}{$\begin{array}{l}\text { \% Nucleotide differences } \\
\text { in the following } \\
\text { rRNA regions }{ }^{b} \text { : }\end{array}$} \\
\hline & & & & $18 \mathrm{~S}$ & $25 S-635$ & $25 S-1841$ \\
\hline Saccharomyces cerevisiae $\times$ Saccharomyces pastorianus & 58 & - & - & 0 & 5.4 & 1.4 \\
\hline Saccharomyces cerevisiae $\times$ Saccharomyces bayanus & 10 & - & - & 0 & 5.4 & 1.4 \\
\hline Saccharomyces pastorianus $\times$ Saccharomyces bayanus & 70 & - & 一 & 0 & 0 & 0 \\
\hline Pichia mississippiensis $\times$ Pichia amylophila & $20-27$ & Good conjugation & Not viable & 0 & 2.0 & 0 \\
\hline Pichia bimundalis $\times$ Pichia americana & 21 & Poor conjugation & No ascospores & $\mathbf{0}$ & 1.0 & 0 \\
\hline $\begin{array}{l}\text { Issatchenkia scutulata var. scutulata } \times \text { Issatchenkia } \\
\text { scutulata } \text { var. exigua }\end{array}$ & $21-26$ & Good conjugation & $\mathrm{F}_{1}, 5 \% ; \mathrm{F}_{2}, 17 \%$ & 0 & 5.1 & 0.6 \\
\hline
\end{tabular}

${ }^{a}$ Data from references 24 and 45 .

${ }^{b}$ The numbers of nucleotides sequenced were as follows: region, 18S-566, 86 nucleotides; region 18S-901, 153 nucleotides; region $18 \mathrm{~S}-1137$, 122 nucleotides; region 18S-1627, 145 nucleotides; region 25S-635, 201 nucleotides; region 25S-1841, 148 nucleotides. Data from reference 40.

c - Data not available.

highly variable region, designated $25 \mathrm{~S}-635$, allowed separation of closely related species.

Some apparent differences in rates of substitution were observed among the species pairs. Saccharomyces cerevisiae and Saccharomyces bayanus exhibited approximately $5 \%$ nucleotide divergence, whereas Saccharomyces bayanus and Saccharomyces pastorianus had the same sequence. Levels of difference for the other species pairs were 1 to $5 \%$. Vaughan Martini and Kurtzman had postulated previously that Saccharomyces pastorianus represents a partial amphidiploid that arose from a chance hybridization between Saccharomyces cerevisiae and Saccharomyces bayanus (45). If this is true, Saccharomyces pastorianus seems to have received from Saccharomyces bayanus that portion of the chromosome which carries the rRNA genes. The mechanism of species formation for the other sibling pairs is unknown, but if genetic isolation included chromosomal rearrangements, the impression of differing rates of substitution could result.

The number of nucleotide differences among strains of a species has proven to be remarkably small. Examination of a variety of ascomycetous and basidiomycetous taxa has shown that strains of many species exhibit no variation in the variable 300 -nucleotide $25 S-635$ region $(13,19,20,25,26)$. The strains of other species may differ by two nucleotides in this region, as was found for Schizosaccharomyces pombe (29). The only exception found so far concerns strains of Williopsis californica (34); isolates of this species differ by up to eight nucleotides in region 25S-635, but the differences are mainly contiguous deletions. Consequently, with few exceptions, species can be separated from each other on the basis of differences in region $25 \mathrm{~S}-635$.

The resolution afforded at greater distances was investigated by Kurtzman and Robnett (29), who examined species assigned to the genera Saccharomyces, Schizosaccharomyces, Debaryomyces, and Schwanniomyces. Figure 1 is a phylogenetic tree which shows species relationships within these genera. This tree shows that despite atypical ascospore ornamentation, Debaryomyces marama is quite closely related to Debaryomyces hansenii, whereas Debaryomyces tamarii, a phenotypically unusual species, is misplaced. Schwanniomyces occidentalis was included in the study because of its overall phenotypic similarity to species of the genus Debaryomyces. The pattern of sequences shown by Schwanniomyces occidentalis suggests that despite its different ascospore ornamentation, this species is more properly placed in the genus Debaryomyces.
Examination of sequences from additional ascomycetous taxa has shown that the mucoid soil yeast genus Lipomyces and its apparent anamorph, the genus Myxozyma, are phylogenetically well separated from other budding species (27). For taxa with saturnoid ascospores, species previously assigned to the genus Pichia have been found to represent a genetically distinct cluster that is phylogenetically distant from the saturn-spored genus Williopsis (34).

Among basidiomycetous yeasts, rRNA sequence differences show that teliosporic taxa, including carotenoid producers and non-carotenoid producers, form a cluster that is distinct from the species whose sexual cycle contains no teliospores $(13,19,20)$. Carotenoid producers can be further recognized by a distinct ca. 20-nucleotide deletion that begins at base 430 in region $25 \mathrm{~S}-635$.

Barns et al. (4) examined relationships among a wide variety of ascomycetous Candida spp. by using approximately 1,200 positions in the $18 \mathrm{~S}$ subunit. Consistent with the results of $5 \mathrm{~S}$ comparisons (48), Yarrowia (Candida) lipolytica was among the more divergent species. The medically important species Candida albicans, Candida viswanathii, Candida tropicalis, Candida parapsilosis, and Candida guilliermondii formed a cluster of relatively closely related organisms, but other pathogens, such as Candida glabrata, were more distantly related.

\section{NUCLEOTIDE SUBSTITUTION RATES AND ESTIMATES OF PHYLOGENETIC DISTANCES}

Calculations of phylogenetic distances from changes in the sequences of macromolecules require that substitutions occur at a predictable rate and preferably a rate that is also constant. Ochman and Wilson (38) reported that nucleotide substitutions in small-subunit (16S to 18S) rRNAs from both prokaryotes and eukaryotes proceed at the same rate $(1 \%$ per $50 \times 10^{6}$ years). Other workers, however, have presented evidence that rates of nucleotide substitution differ among phylogenetic groups and possibly among species within groups $(9,15,50)$. Methods for calculating evolutionary relationships based on macromolecular changes have been described $(2,14,22,32,52)$, and some of the algorithms are designed to compensate for disproportional rates of substitution, but there still appears to be considerable uncertainty concerning the reliability of these methods (14). For example, evolutionary relationships among the bacteria are still subject to debate $(1,18,32)$.

Relatively little is known about the phylogeny of yeasts 


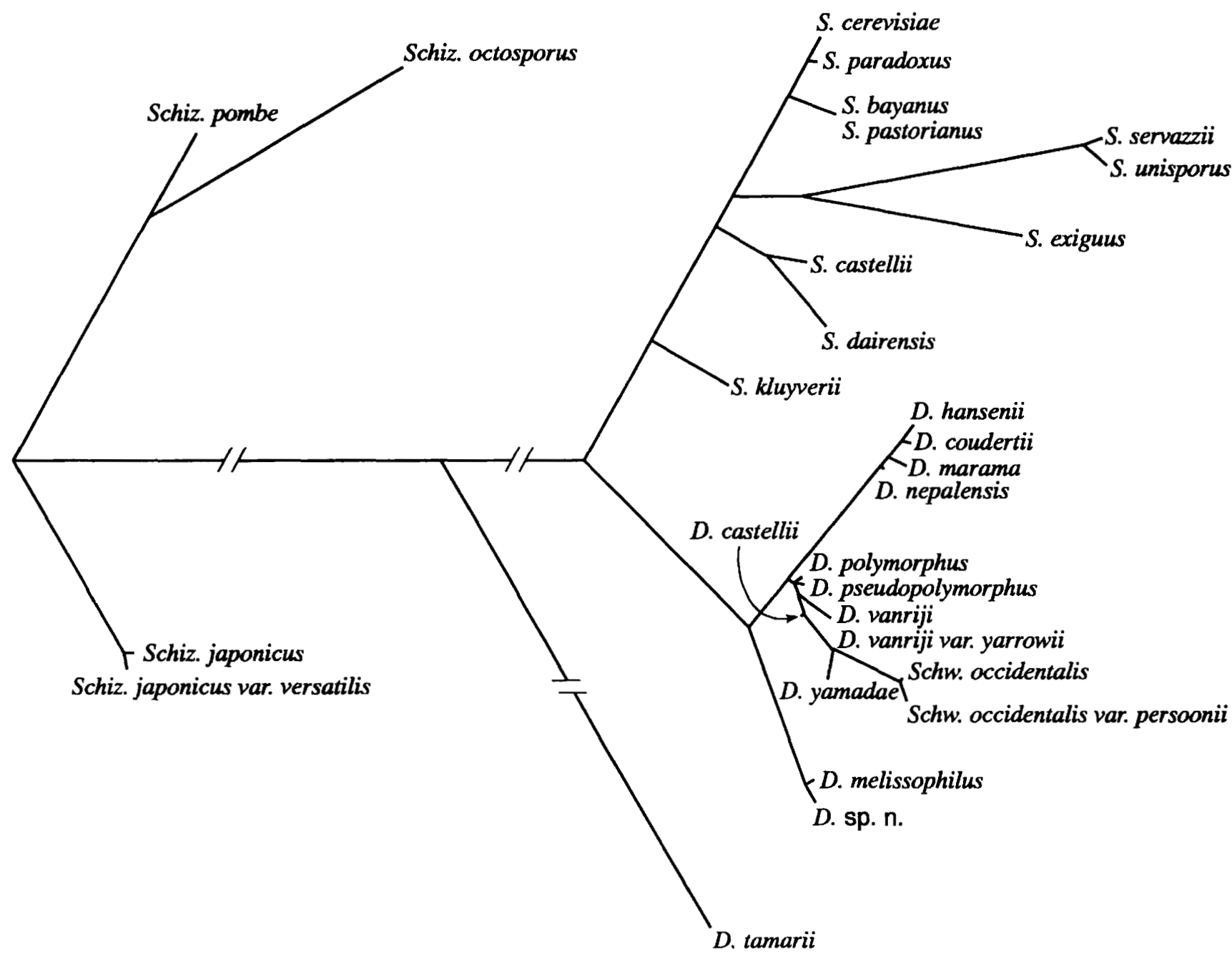

FIG. 1. Phylogenetic tree of species of the genera Saccharomyces, Debaryomyces, Schwanniomyces, and Schizosaccharomyces determined by using the combined large- and small-subunit rRNA sequences (900 nucleotides) and the algorithm DNAML (version 3.11) as described by Kurtzman and Robnett (30). Branches interrupted by double lines are shown at one-half of their computed lengths. Uncertainty concerning branch lengths is discussed in the text, and an alternative analysis of intergeneric branch lengths is shown in Fig. 2. S., Saccharomyces; D., Debaryomyces; Schw., Schwanniomyces; Schiz., Schizosaccharomyces.

and the reliability of assessing relationships on the basis of rRNA substitutions. Close relationships have been measured from comparisons of sibling species. Some data on rates of substitution among more distantly related taxa are now available. One means for assessing rates of substitution is the outlier method (37). In this procedure, a group of closely related taxa is compared with a distantly related species. If there are differences in the rates of substitution

TABLE 2. Percentages of nucleotide differences in rRNA regions of budding and fission yeasts as determined by pairwise comparisons ${ }^{a}$

\begin{tabular}{|c|c|c|c|c|c|c|c|c|c|c|c|c|}
\hline \multirow[b]{3}{*}{ Species } & \multicolumn{12}{|c|}{$\%$ Nucleotide differences in: } \\
\hline & \multicolumn{4}{|c|}{ Region $25 \mathrm{~S}-635$} & \multicolumn{4}{|c|}{ Region 25S-1841 } & \multicolumn{4}{|c|}{ Region $18 \mathrm{~S}-1627$} \\
\hline & $\begin{array}{c}\text { Schizosac- } \\
\text { charomyces } \\
\text { japonicus } \\
\text { var. } \\
\text { versatilis }\end{array}$ & $\begin{array}{l}\text { Saccharo- } \\
\text { myces } \\
\text { cerevisiae }\end{array}$ & $\begin{array}{c}\text { Pichia } \\
\text { bimun- } \\
\text { dalis }\end{array}$ & $\begin{array}{l}\text { Issatch- } \\
\text { enkia } \\
\text { scutulata }\end{array}$ & $\begin{array}{c}\text { Schizosac- } \\
\text { charomyces } \\
\text { japonicus } \\
\text { var. } \\
\text { versatilis }\end{array}$ & $\begin{array}{l}\text { Saccharo- } \\
\text { myces } \\
\text { cerevisiae }\end{array}$ & $\begin{array}{c}\text { Pichia } \\
\text { bimun- } \\
\text { dalis }\end{array}$ & $\begin{array}{l}\text { Issatch- } \\
\text { enkia } \\
\text { scutulata }\end{array}$ & $\begin{array}{c}\text { Schizosac- } \\
\text { charomyces } \\
\text { japonicus } \\
\text { var. } \\
\text { versatilis }\end{array}$ & $\begin{array}{l}\text { Saccharo- } \\
\text { myces } \\
\text { cerevisiae }\end{array}$ & $\begin{array}{c}\text { Pichia } \\
\text { bimun- } \\
\text { dalis }\end{array}$ & $\begin{array}{l}\text { Issatch- } \\
\text { enkia } \\
\text { scutulata }\end{array}$ \\
\hline $\begin{array}{l}\text { Saccharomyces cerevi- } \\
\text { siae }\end{array}$ & 40.8 & & & & 28.4 & & & & 15.0 & & & \\
\hline Pichia bimundalis & 46.9 & 29.9 & & & 29.1 & 11.2 & & 14.0 & 3.6 & & & \\
\hline Issatchenkia scutulata & 45.7 & 34.0 & 34.0 & & 33.7 & 13.5 & 18.0 & & 16.8 & 7.0 & 6.5 & \\
\hline Pichia mississippiensis & 46.3 & 29.2 & 2.1 & 33.5 & 31.4 & 14.0 & 3.4 & 17.6 & 15.1 & 4.2 & 0.0 & 6.6 \\
\hline
\end{tabular}

${ }^{a}$ Data from reference 40 

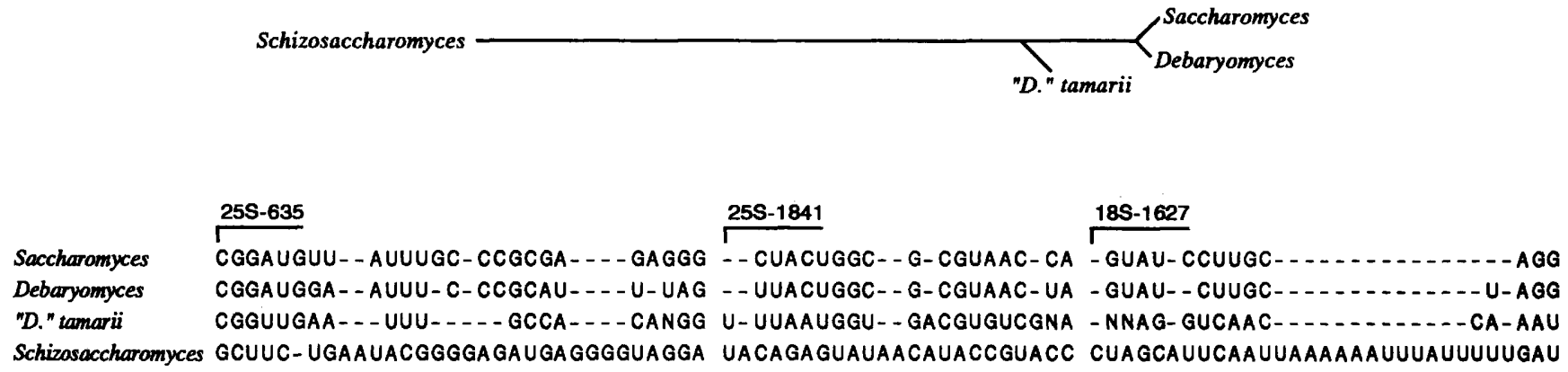

FIG. 2. Phylogenetic tree of the genus Saccharomyces, the genus Debaryomyces, D. tamarii, and the genus Schizosaccharomyces and the modified data set used for construction of the tree. The nucleotides that were used to make this tree were the nucleotides that are unique to all of the species of each genus but are not common to all of the genera. The removal of all sites having deletions changed the calculated branch lengths by about $5 \%$. The phylogenetic distance between the budding and fission yeasts shown here is about three times the distance shown in Fig. 1, but the distance between $D$. tamarii and the other budding yeasts is markedly shorter.

among members of the closely related group, they have different numbers of nucleotide substitutions when they are compared with the outlier. Peterson and Kurtzman (40) used Schizosaccharomyces japonicus as an outlier to determine whether differences in rates of substitution occur in budding yeasts (Table 2). All of the organisms studied had the same number of substitutions, but it seemed likely that a plateauing had occurred and that the major differences were qualitative, with substitutions occurring in different areas of the regions examined. As a consequence, this suggests that the distance between highly evolved taxa is underestimated if the calculation is based solely on numbers of substitutions. An example of this is found in the phylogenetic tree shown in Fig. 1, where the branches between the genera Saccharomyces, Debaryomyces, and Schizosaccharomyces seem quite short and probably underestimate the intergeneric distances. An alternate calculation based on a data set comprising nucleotides unique to each genus resulted in a considerably longer branch between fission and budding yeasts (Fig. 2) and appeared to be more in accord with estimates of phylogenetic distances obtained from sequence comparisons of 5S rRNAs (36) and cytochrome $c$ molecules (44).

Consequently, it appears that estimates of phylogeny must be based not only on differences in nucleotide number, but also on the information provided by unique sequence patterns or signatures. Whether the areas seen as signature nucleotides are conserved because they confer physiological advantages in certain ecological niches is unknown. Nonetheless, the presence of these areas raises questions about the constancy of the rRNA molecular clock. Signatures have been identified for the genera Saccharomyces, Debaryomyces, and Schizosaccharomyces and many other genera (13, $19,20,25,26,34,39,53)$, but one notable exception is the genus Williopsis. Not only do the five species that form this generic federation lack apparent common signatures, but the sequences also differ from one another at many positions. As a result, the phenotypic characteristics that define this genus mask the genetic divergence present and have led to the construction of what may be analogous to the form genus of anamorphic fungi. The definition of genera as both taxonomic and evolutionary entities will require additional studies and perhaps some philosophical considerations.

\section{CONCLUSIONS}

While it is still early, the studies that have been completed suggest that comparisons of rRNAs will significantly influ- ence our perception of yeast systematics and its implicit reflection of evolution among the fungi. It is already apparent that a practical application of the work will be the development of taxon-specific oligonucleotide probes for rapid identification of medically, agriculturally, and industrially significant organisms. However, additional comparative studies are needed to better understand the temporal aspects of nucleotide changes and their resulting impact on estimates of relatedness.

\section{REFERENCES}

1. Achenbach-Richter, L., R. Gupta, W. Zillig, and C. R. Woese. 1988. Rooting the archaebacterial tree: the pivotal role of Thermococcus celer in archaebacterial evolution. Syst. Appl. Microbiol. 10:231-240.

2. Avise, J. 1989. Gene trees and organismal histories: a phylogenetic approach to population biology. Evolution 43:1192-1208.

3. Baharaeen, S., and H. S. Vishniac. 1984. 25S ribosomal RNA homologies of basidiomycetous yeasts: taxonomic and phylogenetic implications. Can. J. Microbiol. 30:613-621.

4. Barns, S. M., D. J. Lane, M. L. Sogin, C. Bibeau, and W. G. Weisburg. 1991. Evolutionary relationships among pathogenic Candida species and relatives. J. Bacteriol. 173:2250-2255.

5. Bicknell, J. N., and H. C. Douglas. 1970. Nucleic acid homologies among species of Saccharomyces. J. Bacteriol. 101:505512 .

6. Blanz, P. A., and M. Gottschalk. 1984. A comparison of 5 S ribosomal RNA nucleotide sequences from smut fungi. Syst. Appl. Microbiol. 5:518-526.

7. Blanz, P. A., and M. Gottschalk. 1986. Systematic position of Septobasidium, Graphiola and other basidiomycetes as deduced on the basis of their 5S ribosomal RNA nucleotide sequences. Syst. Appl. Microbiol. 8:121-127.

8. Bonner, T. I., D. J. Brenner, B. R. Neufeld, and R. J. Britten. 1973. Reduction in the rate of DNA reassociation by sequence divergence. J. Mol. Biol. 81:123-135.

9. Britten, R. J. 1986. Rates of DNA sequence evolution differ between taxonomic groups. Science 231:1393-1398.

10. Britten, R. J., D. E. Graham, and B. R. Neufeld. 1974. Analysis of repeating DNA sequences by reassociation. Methods Enzymol. 29:363-418.

11. Chirgwin, J. M., A. E. Przybyla, R. J. MacDonald, and W. J. Rutter. 1979. Isolation of biologically active ribonucleic acid from sources enriched in ribonuclease. Biochemistry 18:5284 5299.

12. Dams, E., I. Hendriks, Y. Van de Peer, J.-M. Neefs, G. Smits, I. Vandenbempt, and R. De Wachter. 1988. Compilation of small ribosomal subunit RNA sequences. Nucleic Acids Res. 16:r87r173.

13. Fell, J. W., and C. P. Kurtzman. 1990. Nucleotide sequence analysis of a variable region of the large subunit rRNA for 
identification of marine-occurring yeasts. Curr. Microbiol. 21: 295-300.

14. Felsenstein, J. 1988. Phylogenies from molecular sequences: inference and reliability. Annu. Rev. Genet. 22:521-565.

15. Field, K. G., G. J. Olsen, D. J. Lane, S. J. Giovannoni, M. T. Chiselin, E. C. Raff, N. R. Pace, and R. A. Raff. 1988. Molecular phylogeny of the animal kingdom. Science 239:748-753.

16. Garber, R. C., B. G. Turgeon, E. U. Selker, and O. C. Yoder. 1988. Organization of ribosomal RNA genes in the fungus Cochliobolus heterostrophus. Curr. Genet. 14:573-582.

17. Gottschalk; M., and P. A. Blanz. 1984. Highly conserved 5 S ribosomal RNA sequences in four rust fungi and atypical $5 \mathrm{~S}$ rRNA secondary structure in Microstroma juglandis. Nucleic Acids Res. 12:3951-3958.

18. Gouy, M., and W.-H. Li. 1989. Phylogenetic analysis based on rRNA sequences supports the archaebacterial rather than the eocyte tree. Nature (London) 339:145-147.

19. Guého, E., C. P. Kurtzman, and S. W. Peterson. 1989. Evolutionary affinities of heterobasidiomycetous yeasts estimated from $18 \mathrm{~S}$ and $25 \mathrm{~S}$ ribosomal RNA sequence divergence. Syst. Appl. Microbiol. 12:230-236.

20. Guého, E., C. P. Kurtzman, and S. W. Peterson. 1990. Phylogenetic relationships among species of Sterigmatomyces and Fellomyces as determined from partial rRNA sequences. Int. J. Syst. Bacteriol. 40:60-65.

21. Gutell, R. R., and G. E. Fox. 1988. Compilation of large subunit RNA sequences presented in a structural format. Nucleic Acids Res. 16:r175-r269.

22. Holmquist, R., M. M. Miyamoto, and M. Goodman. 1988. Analysis of higher-primate phylogeny from transversion differences in nuclear and mitochondrial DNA by Lake's method of evolutionary parsimony and operator metrics. Mol. Biol. Evol. $5: 217-236$

23. Hori, H., and S. Osawa. 1979. Evolutionary change in 5S RNA secondary structure and a phylogenetic tree of 54 5S RNA species. Proc. Natl. Acad. Sci. USA 76:381-385.

24. Kurtzman, C. P. 1987. Prediction of biological relatedness among yeasts from comparisons of nuclear DNA complementarity. Stud. Mycol. 30:459-468.

25. Kurtzman, C. P. 1989 . Estimation of phylogenetic distances among ascomycetous yeasts from partial sequencing of ribosomal RNA. Yeast 5:S351-S354.

26. Kurtzman, C. P. 1990. Candida shehatae-genetic diversity and phylogenetic relationships with other xylose-fermenting yeasts. Antonie van Leeuwenhoek 57:215-222.

27. Kurtzman, C. P., and Z. Liu. 1990. Evolutionary affinities of species assigned to Lipomyces and Myxozyma estimated from ribosomal RNA sequence divergence. Curr. Microbiol. 21:387393.

28. Kurtzman, C. P., and H. J. Phaff. 1987. Molecular taxonomy, p. 63-94. In A. H. Rose and J. S. Harrison (ed.), The yeasts, vol. 1. Biology of yeasts. Academic Press, Ltd., London.

29. Kurtzman, C. P., and C. J. Robnett. 1991. Phylogenetic relationships among species of Saccharomyces, Schizosaccharomyces, Debaryomyces and Schwanniomyces determined from partial ribosomal RNA sequences. Yeast 7:61-72.

30. Laaser, G., E. Moller, K.-D. Jahnke, G. Bahnweg, H. Prillinger, and H. H. Prell. 1989. Ribosomal DNA restriction fragment analysis as a taxonomic tool in separating physiologically similar basidiomycetous yeasts. Syst. Appl. Microbiol. 11:170-175.

31. Lachance, M.-A. 1990. Ribosomal DNA spacer variation in the cactophilic yeast Clavispora opuntiae. Mol. Biol. Evol. 7:178193.

32. Lake, J. A. 1987. A rate-independent technique for analysis of nucleic acid sequences: evolutionary parsimony. Mol. Biol. Evol. 4:167-191

33. Lane, D. J., B. Pace, G. J. Olsen, D. A. Stahl, M. L. Sogin, and N. R. Pace. 1985. Rapid determination of 16 S ribosomal RNA sequences for phylogenetic analyses. Proc. Natl. Acad. Sci. USA 82:6955-6959.
34. Liu, Z., and C. P. Kurtzman. Phylogenetic relationships among species of Williopsis and Saturnospora gen. nov. as determined from partial rRNA sequences. Antonie van Leeuwenhoek, in press.

35. Magee, B. B., T. M. D'Souza, and P. T. Magee. 1987. Strain and species identification by restriction fragment length polymorphisms in the ribosomal DNA repeat of Candida species. J Bacteriol. 169:1639-1643.

36. Mao, J., B. Appel, J. Schaack, S. Sharp, H. Yamada, and D. Soll. 1982. The 5S RNA genes of Schizosaccharomyces pombe Nucleic Acids Res. 10:487-500.

37. McCarroll, R., G. J. Olsen, Y. D. Stahl, C. R. Woese, and M. L. Sogin. 1983. Nucleotide sequence of the Dictyostelium discoi deum small-subunit ribosomal ribonucleic acid inferred from the gene sequence: evolutionary implications. Biochemistry 22: 5858-5868.

38. Ochman, H., and A. C. Wilson. 1987. Evolution in bacteria: evidence for a universal substitution rate in cellular genomes. $J$. Mol. Evol. 26:74-86.

39. Peterson, S. W., and C. P. Kurtzman. 1990. Phylogenetic relationships among species of the genus Issatchenkia Kudriavzev. Antonie van Leeuwenhoek 58:235-240.

40. Peterson, S. W., and C. P. Kurtzman. 1991. Ribosomal RNA sequence divergence among sibling species of yeasts. Syst Appl. Microbiol, 14:124-129.

41. Sanger, F., S. Nicklen, and A. R. Coulson. 1977. DNA sequencing with chain-terminating inhibitors. Proc. Natl. Acad. Sci. USA 74:5463-5467.

42. Segal, E., and E. Eylan. 1974. Genetic relatedness of Candida albicans to asporogenous and ascosporogenous yeasts as reflected by nucleic acid homologies. Microbios 9:25-33.

43. Segal, E., and E. Eylan. 1974. Nucleic acid homologies between Candida albicans and Hansenula species. Microbios 10:133138.

44. Simon-Becam, A.-M., M. Claisse, and F. Lederer. 1978. Cytochrome $c$ from Schizosaccharomyces pombe. Eur. J. Biochem. 86:407-416.

45. Vaughan Martini, A., and C. P. Kurtzman. 1985. Deoxyribonucleic acid relatedness among species of the genus Saccharomyces sensu stricto. Int. J. Syst. Bacteriol. 35:508-511.

46. Vilgalys, R., and M. Hester. 1990. Rapid genetic identification and mapping of enzymatically amplified ribosomal DNA from several Cryptococcus species. J. Bacteriol. 172:4238-4246.

47. Walker, W. F. 1984. 5S rRNA sequences from Atractiellales, and basidiomycetous yeasts and fungi imperfecti. Syst. Appl. Microbiol. 5:352-359.

48. Walker, W. F. 1985. 5S ribosomal RNA sequences from ascomycetes and evolutionary implications. Syst. Appl. Microbiol. 6:48-53.

49. Walker, W. F., and W. F. Doolittle. 1982. Redividing the basidiomycetes on the basis of SS rRNA nucleotide sequences. Nature (London) 299:723-724

50. Weisburg, W. G., J. G. Tully, D. L. Rose, J. P. Petzel, H. Oyaizu, D. Yang, L. Mandelco, J. Sechrest, T. B. Lawrence, J. Van Etten, J. Maniloff, and C. R. Woese. 1989. A phylogenetic analysis of the mycoplasmas: basis for their classification. $\mathbf{J}$. Bacteriol. 171:6455-6467.

51. White, T. J., T. Bruns, S. Lee, and J. Taylor. 1990. Amplification and direct sequencing of fungal ribosomal RNA genes for phylogenetics, p. 315-322. In N. Innis, D. Gelfand, J. Sninsky, and T. White (ed.), PCR protocols: a guide to methods and applications. Academic Press, Inc., New York.

52. Woese, C. R. 1987. Bacterial evolution. Microbiol. Rev. 51:221271.

53. Yamada, Y., Y. Nakagawa, and I. Banno. 1989. The phylogenetic relationship of the $\mathrm{Q}_{9}$-equipped species of the heterobasidiomycetous yeast genera Rhodosporidium and Leucosporidium based on the partial sequences of $18 \mathrm{~S}$ and $26 \mathrm{~S}$ ribosomal nucleic acids: the proposal of a new genus Kondoa. J. Gen. Appl. Microbiol. 35:377-385. 